\title{
MODELLING OF POST-TENSIONED TIMBER-FRAMED BUILDINGS WITH SEISMIC ROCKING MECHANISM AT THE COLUMN-FOUNDATION CONNECTIONS
}

\author{
FELICE CARLO PONZO ${ }^{1}$, ANTONIO DI CESARE ${ }^{1}$, NICLA LAMARUCCIOLA $^{1}$, \\ DOMENICO NIGRO ${ }^{1} \&$ STEFANO PAMPANIN ${ }^{2}$ \\ ${ }^{1}$ School of Engineering, University of Basilicata, Potenza, Italy. \\ ${ }^{2}$ Department of Civil and Natural Resources Engineering, University of Canterbury, Christchurch, New Zealand.
}

\begin{abstract}
The need to mitigate damage of buildings even after strong earthquakes has led to the development of high-performance seismic resisting systems. Extensive studies have been made in the last decade on the development and use of jointed ductile connections and on the effects of rocking vibration systems in reducing seismic damage of buildings. A recently developed technology for construction of multistorey timber buildings called Pres-Lam system uses long lengths of prefabricated laminated timber and binds them together using pre-stressing steel tendons. When appropriately combining unbounded posttensioned tendons, or rocking columns with additional sources of energy dissipation devices, a hybrid system is obtained, with self-centering and dissipative properties, leading to a characteristic flag-shape hysteresis behaviour.

A three-dimensional, three-storey, two-third scaled, post-tensioned timber frame model was tested at the structural laboratory of the University of Basilicata. During shaking table tests, two different configurations of the test model have been studied considering column-table connections with and without the activation of dissipative steel angles. This paper focuses on different numerical modelling of the rocking mechanisms at the column-foundation connections. Two different modelling have been considered for two different test configurations by means of a pinned base or an appropriate combination of nonlinear rotational springs, for free rocking and a suitable combination of gap elements and linear springs or rotational springs, for dissipative rocking. The numerical outcomes of nonlinear dynamic analysis are compared with experimental test results providing an adequate representation of the seismic response.

Keywords: dissipative rocking mechanism, free rocking mechanism, nonlinear modeling, post-tensioned timber frame, shaking table testing.
\end{abstract}

\section{INTRODUCTION}

Due to its favourable properties, timber material has been used for thousands of years to construct buildings. Currently, there is an increased trend to consider multi-storey buildings using again timber as construction material, optimising the structural concept and design, with the requirement to be functional or recovered promptly even after strong earthquakes. Some research have explained that the effects of rocking vibration can reduce seismic damage of buildings subjected to strong earthquake ground motion [1-3]. Based on this knowledge, some rocking structural system have been proposed and developed [4, 5]. A recent technology, called Pres-Lam system, originally developed for precast concrete frame and wall systems, has been particularly successful for seismic areas [6, 7] and uses post-tensioning concept normally combined with dissipative reinforcing devices in order to connect structural timber elements $[8,9]$. While the post-tensioning contribution $\left(\mathrm{M}_{\mathrm{pt}}\right)$, or the axial load contribution in case of columns $\left(\mathrm{M}_{\mathrm{N}}\right)$, provides desirable re-centring properties, the dissipative devices provide adequate energy dissipation as well as increased moment resistance $\left(\mathrm{M}_{\mathrm{s}}\right)$. During lateral movement, a controlled rocking occurs at the beam-column and column-foundation interface which gives the 'flag shaped' hysteretic behaviour [10,11]. 
This paper focuses on two different numerical modelling of base rocking mechanisms, examining the global non-linear dynamic response of post-tensioned timber-framed buildings with controlled rocking vibration mechanism at the base of the columns, both with and without energy dissipation devices (dissipative and free rocking, respectively). During a collaborative experimental campaign between the University of Basilicata and the University of Canterbury a three-dimensional, three-storey, two-third scaled Pres-Lam frame specimen, designed to withstand high levels of seismic loading without damage, has been dynamically tested on shaking table in the structural laboratory of University of Basilicata. The experimental testing results have been compared with the numerical responses in order to confirm the effectiveness of the different modelling techniques in predicting the seismic performance of different configurations of the experimental Pres-Lam specimen.

\section{EXPERIMENTAL MODEL AND TESTING PROGRAMME}

The prototype building tested at UNIBAS Laboratory was three-dimensional, three-storey and had single bays in both directions. The inter-storey height was $3 \mathrm{~m}$ and the frame footprint equal to $6 \mathrm{~m} \times 4.5 \mathrm{~m}$. A scale factor of two-third was applied to the prototype building obtaining an inter-storey height of $2 \mathrm{~m}$ and a scaled structure footprint of $4 \mathrm{~m} \mathrm{x} 3 \mathrm{~m}$ (Fig. 1). The test frame was made of Glulam grade GL32h [12], it was post-tensioned in both the Primary $(\mathrm{P})$ and Secondary $(\mathrm{S})$ directions with the post-tensioning bars crossing at the beam-column joint. During dynamic testing, the passive hysteretic devices, which are designed to yield in a controlled manner, were added to the Pres-Lam structure at

(a)

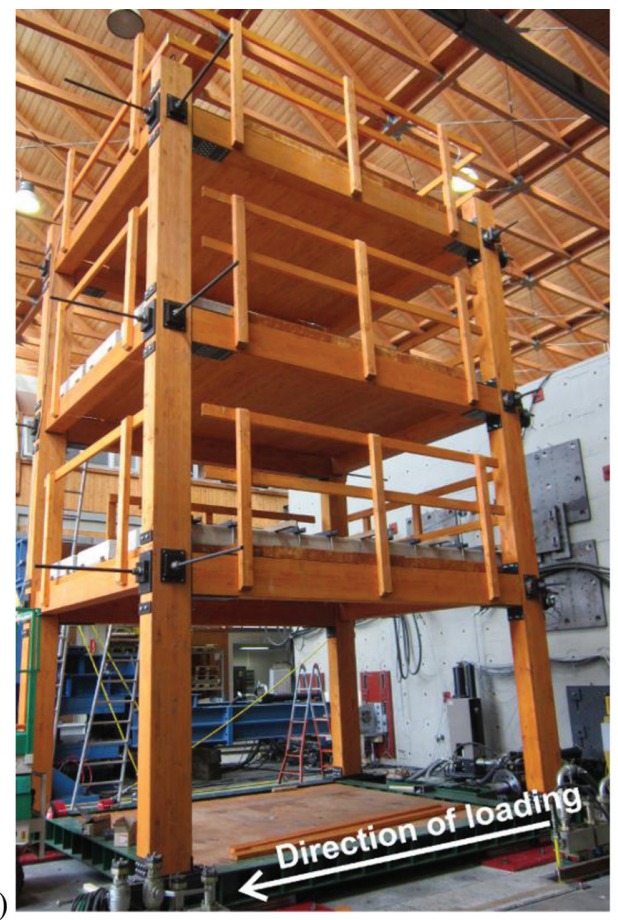

(b)

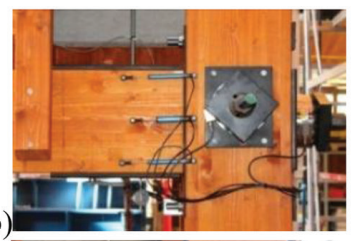

(c)

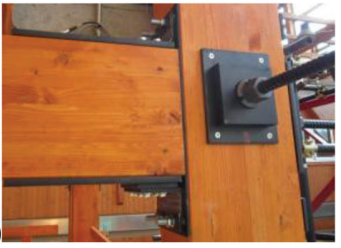

(d)

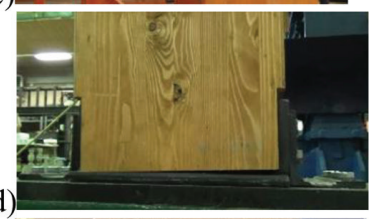

(e)

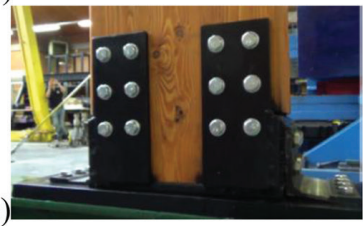

Figure 1: (a) Experimental model tested at UNIBAS laboratory; Beam-column connection (b) without and (c) with dissipative steel angles; Column-foundation connection for: (d) Session 1 with free rocking; (e) Session 2 with dissipative rocking. 
beam-column and column-foundation connections, in order to increase strength and stiffness and reduce displacements without increasing acceleration or base shear [13, 14]. During a seismic event, the Pres-Lam system uses controlled rocking vibration to provide non-linear response and activate the dissipative devices and this system can reduce earthquake responses of structures. The base of the column was fitted with a steel shoe, which is epoxied into the base of the column and left free to rock on a base plate creating free rocking between the column and foundation (Session 1 testing). Then, the base of the column was fitted with four 10-mm-thick plates that were welded to the each base plate and coach bolted to the side of the column in order to activate the dissipative devices leading to Dissipative Rocking (Session 2 testing). Both Sessions 1 and 2 testing were performed with and without dissipation at beam-column (Fig. 1b,c). Between Session 1 and Session 2 testing (Table 1), all aspects of the test specimen remained the same except for the column base connection: Session 1 testing with Free Rocking (Fig. 1d); Session 2 testing with Dissipative Rocking (Fig. 1e). The test frame was designed using displacement-based design to set target performance parameters. Design drift levels of $2.0 \%$ and $2.5 \%$ under ultimate limit state (PGA 100\%) loading were selected for the testing configuration with and without dissipation at the beam-column joint, respectively. Forty-eight instruments were placed upon the structure to evaluate the experimental dynamic behaviour and connection deformation in real time. The testing input consisted of seven spectra compatible earthquakes selected from the European strong-motion database. The code spectrum used to select this set corresponded to a high seismic zone having a PGA of $0.44 \mathrm{~g}$ (Soil class B - medium soil, [15]). In order to match the real acceleration inputs to the code spectrum, it was necessary to scale some input earthquakes. This paper discusses in detail the experimental results considering a smaller set of two ground motions which provide a good representation of the design spectra (Fig. 2). For more information about the experimental model, connection details and instrumentation please refer to [16].

Table 1: Testing sessions.

\begin{tabular}{llll}
\hline Testing & & Dissipative angles & \\
\hline Sessions & Configurations & Beam-column & Column-foundation \\
\hline Session 1 & Without dissipation & NO & NO \\
& With dissipation & YES & NO \\
Session 2 & Without dissipation & NO & YES \\
& With dissipation & YES & YES \\
\hline
\end{tabular}

\begin{tabular}{|c|c|c|c|}
\hline $\begin{array}{l}\text { ID } \\
\text { code }\end{array}$ & Location & $\mathrm{M}_{\mathrm{W}}$ & $\begin{array}{l}\text { PGA } \\
(\mathrm{g})\end{array}$ \\
\hline 196 & $\begin{array}{l}\text { Montenegro } \\
\text { Serbia }\end{array}$ & 6.9 & 0.454 \\
\hline 535 & $\begin{array}{l}\text { Erzican } \\
\text { Turkey }\end{array}$ & 6.6 & 0.769 \\
\hline
\end{tabular}

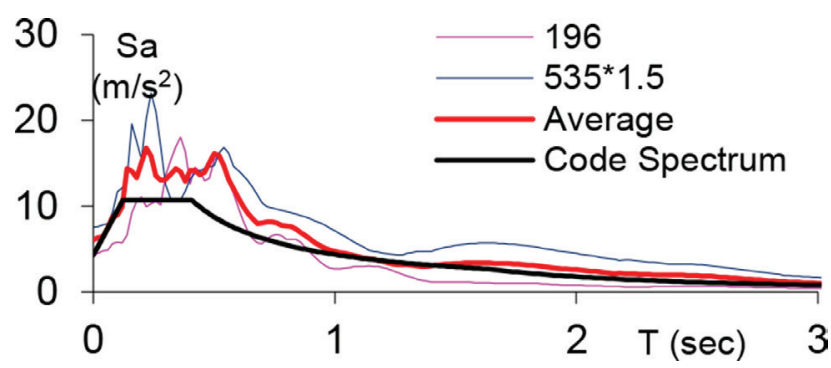

Figure 2: Characteristics of earthquakes and design spectra. 


\section{NUMERICAL MODELLING}

In structural design, it is crucial that simple models exist providing sufficiently accurate building response without requiring a large amount of time in processing or programming. From the beginning of the post-tensioned jointed ductile concept, it has been clear that the nature of the controlled rocking mechanism leant itself well to the use of a lumped plasticity approach which combines the use of elastic elements with springs representing plastic rotations in the system (Fig. 3a). The test frame was modelled using the SAP2000 finite element software to simulate the seismic frame response. Two different numerical models have been studied to represent both free and dissipative rocking mechanisms. The specimen at the beam-column joints was modelled considering a combination of rotational springs to represent the contribution of the post-tensioning and of dissipative devices. The flexibility of the joint panel is accounted for introducing an additional linear rotational spring, with stiffness value opportunely arranged for each model. Post-tensioning response was represented using tri-linear-elastic moment-rotation springs [17] and a Bouc-Wen rotational spring model [18, 19 was used to represent the hysteretic steel elements (Fig. 3b). The varying column axial load complicates the modelling of the column base performance during seismic loading. When dissipative devices are not activated at the column base, such as in Session 1, the column axial load, given by the contribution of gravity plus seismic axial load, provides some moment resistance. A simplified modelling (Model 1) of free rocking at the column-foundation connection is given by the introduction of a perfectly pinned base (PB) constraint (Fig. 4). However, in case of free rocking, this assumption cannot always provide an accurate representation of global seismic response. In order to account base moment contribution, non-linear action of the critical rocking interface has been modelled (Model 2) by using two rotational springs (2RS) in order to represent free rocking mechanism (re-centering springs corresponding to the moment contribution of gravity and seismic axial load), see Fig. 4. Re-centering rotational springs have been calculated by applying an analytical model based on an equilibrium approach to determine varying of axial load caused by seismic action [20].

The characteristics of the numerical models 1 and 2 are reported in Table 2.

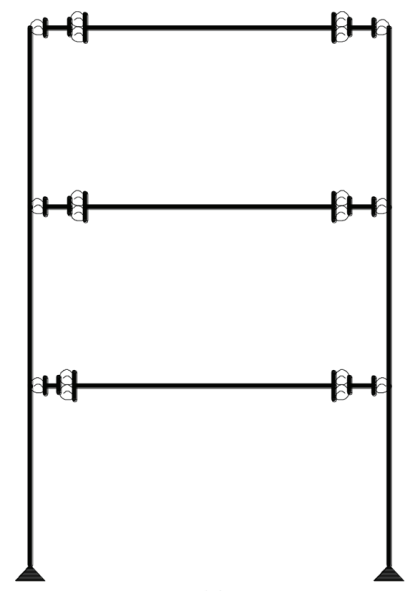

(a)

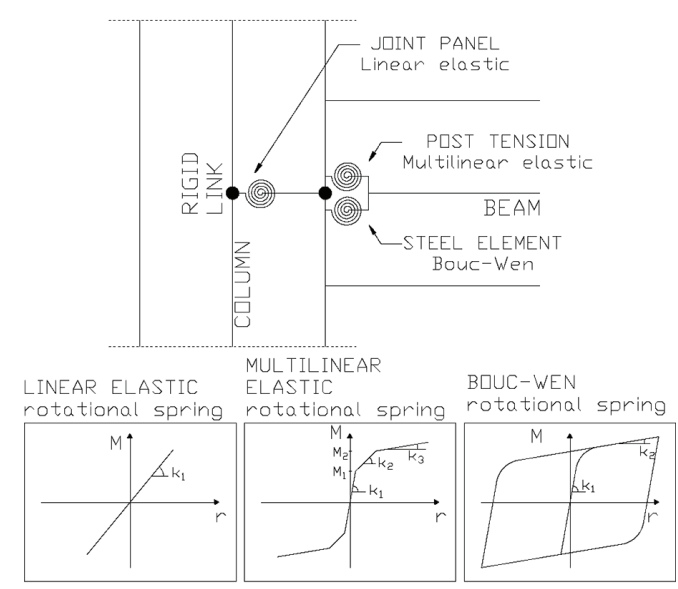

(b)

Figure 3: (a) Numerical modelling of the frame with free rocking at base columns; (b) Details on the numerical modelling adopted for the beam-column joints. 


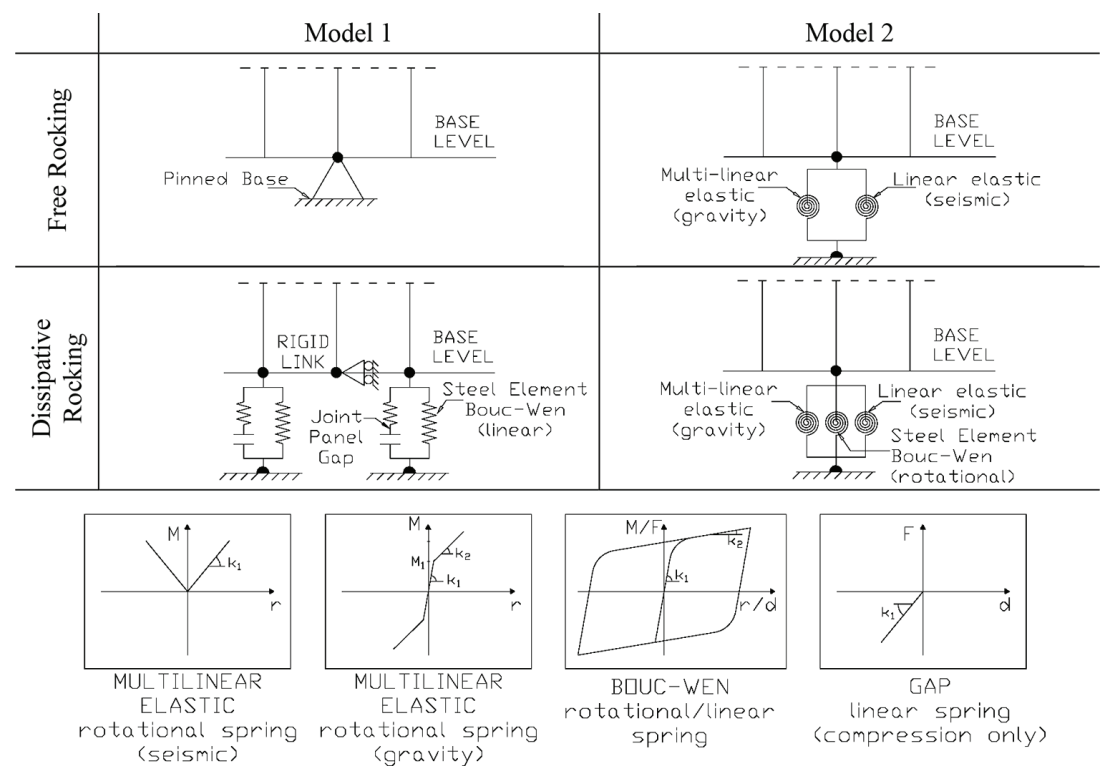

Figure 4: Numerical models of base column connection: Model 1 with Pinned Base (PB) for free rocking and Multi-Spring model (MS) for dissipative rocking; Model 2 with 2 Rotational Springs (2RS) for free rocking and 3 Rotational Springs (3RS) for dissipative rocking.

Table 2: Characteristics of the link elements considered for numerical modelling.

\begin{tabular}{|c|c|c|c|c|c|c|c|}
\hline \multicolumn{3}{|c|}{ Beam-column joint (Model 1 and 2) } & \multirow{2}{*}{$\begin{array}{l}\mathrm{K}_{1} \\
M N \cdot \mathrm{m} / \\
\mathrm{rad}\end{array}$} & \multirow{2}{*}{$\begin{array}{l}\mathrm{M}_{1} \\
k N \cdot m\end{array}$} & \multirow{2}{*}{$\begin{array}{l}\mathrm{K}_{2} \\
M N \cdot \mathrm{m} / \\
\mathrm{rad}\end{array}$} & \multirow{2}{*}{$\begin{array}{l}\mathrm{M}_{2} \\
k N \cdot m\end{array}$} & \multirow{2}{*}{$\begin{array}{l}\mathrm{K}_{3} \\
\begin{array}{l}M N \cdot m / \\
\mathrm{rad}\end{array}\end{array}$} \\
\hline Description & Link type & Behaviour & & & & & \\
\hline Post tension & $\begin{array}{l}\text { Rotational } \\
\text { Spring }\end{array}$ & $\begin{array}{l}\text { Multilinear } \\
\text { Elastic }\end{array}$ & 7.50 & 7.0 & 1.67 & 11.00 & 0.45 \\
\hline Steel element & $\begin{array}{l}\text { Rotational } \\
\text { Spring }\end{array}$ & Bouc-Wen & 1.96 & 10.0 & 0.21 & - & - \\
\hline Joint panel (Model 1) & $\begin{array}{l}\text { Rotational } \\
\text { Spring }\end{array}$ & Linear Elastic & 30.00 & - & - & - & - \\
\hline Joint panel (Model 2) & $\begin{array}{l}\text { Rotational } \\
\text { Spring }\end{array}$ & Linear Elastic & 5.00 & - & - & - & - \\
\hline \multicolumn{3}{|c|}{ Column-foundation connection (Model 1) } & $\mathrm{K}_{1}$ & $\mathrm{~F}_{1}$ & $\mathrm{~K}_{2}$ & - & - \\
\hline Description & Link type & Behaviour & $M N / m$ & $\mathrm{kN}$ & $M N / m$ & - & - \\
\hline Base steel element & Linear Spring & Bouc-Wen & 13.60 & 24.5 & 0.90 & - & - \\
\hline Rocking at the base & Linear Spring & Gap & 2.00 & - & - & - & - \\
\hline
\end{tabular}


Table 2: (Continued)

\begin{tabular}{|c|c|c|c|c|c|c|c|}
\hline \multicolumn{3}{|c|}{ Column-foundation connection (Model 2) } & $\mathrm{K}_{1}$ & $\mathrm{M}_{1}$ & $\mathrm{~K}_{2}$ & - & - \\
\hline Description & Link type & Behaviour & $\begin{array}{l}M N \cdot \mathrm{m} / \\
\mathrm{rad}\end{array}$ & $\mathrm{kN} \cdot \mathrm{m}$ & $\begin{array}{l}\mathrm{MN} \cdot \mathrm{m} / \\
\mathrm{rad}\end{array}$ & - & - \\
\hline Base steel element & $\begin{array}{l}\text { Rotational } \\
\text { Spring }\end{array}$ & Bouc-Wen & 0.80 & 8.00 & 0.13 & - & - \\
\hline $\begin{array}{l}\text { Rocking at the base } \\
\text { (seismic) }\end{array}$ & $\begin{array}{l}\text { Rotational } \\
\text { Spring }\end{array}$ & Linear Elastic & 0.40 & 8.00 & - & - & - \\
\hline $\begin{array}{l}\text { Rocking at the base } \\
\text { (gravity) }\end{array}$ & $\begin{array}{l}\text { Rotational } \\
\text { Spring }\end{array}$ & $\begin{array}{l}\text { Multilinear } \\
\text { Elastic }\end{array}$ & 7.00 & 7.00 & 0.00 & - & - \\
\hline
\end{tabular}

When dissipative devices are applied to the column base, such as in Session 2, an additional moment contribution must be accounted. In the Model 1, dissipative rocking has been modelled with a combination of axial springs [21], or multi-spring model (MS), which accounts for the sudden loss of stiffness due to gap opening but also allows for the change in capacity due to changing axial load (Fig. 4). The multi-spring elements were modelled assigning a restraint to horizontal translation and using two axial gap links and Bouc-Wen linear springs placed in parallel $160 \mathrm{~mm}$ from the column centreline.

In Model 2, a different modelling of dissipative rocking was assumed by the introduction of a third rotational spring (3RS) represented through a Bouc-Wen model, see Fig. 4. Dissipative rotational spring has been calibrated considering a reduction of $50 \%$ of the angles stiffness respect to preliminary testing results. It is to account the lower stiffness of dissipative devices placed at the base column connection than the behaviour of the single steel device tested.

\section{EXPERIMENTAL AND NUMERICAL RESULTS}

The test specimen, presented in the previous section, has been analysed using the results of two different nonlinear dynamic models compared with experimental results. The three key indicators used in order to describe the frames seismic behaviour are first floor drift, third floor acceleration and base shear, for two earthquake cases (196- Montenegro and 535- Erzican, $75 \%$ of PGA). Session 1 and Session 2 results are shown in Figures 5-8, both with and without dissipative steel angle devices at beam-column joints and column-foundation connections.

Figures 5 and 6 show the numerical predictions of Models 1 and 2 for seismic input 196. Both models provide a reliable representation of experimental results of testing Sessions 1 and 2 , only observing variations of the peak values of the base shear. Moreover, few discrepancies of the coda-stage of first floor drift and third floor acceleration have been found for the Model 2 during the testing Session 1 with dissipation.

Figure 7 shows the numerical outcomes of Model 1 and Model 2 for testing Session 1, subjected to seismic input 535. Also, in these cases, numerical results under predict base shear. Few discrepancies of drift peak values have been observed for Model 1 without dissipation and for Model 2 with dissipation.

Figure 8 shows numerical results of both models in case of testing Session 2 for seismic input 535. Models 1 and 2 present an adequate representation of experimental results, both with and without dissipation, only with few discrepancies of peak values of base shear. 
Testing Session 1 - Seismic Input 196 - PGA 75\%

Without dissipation

With dissipation
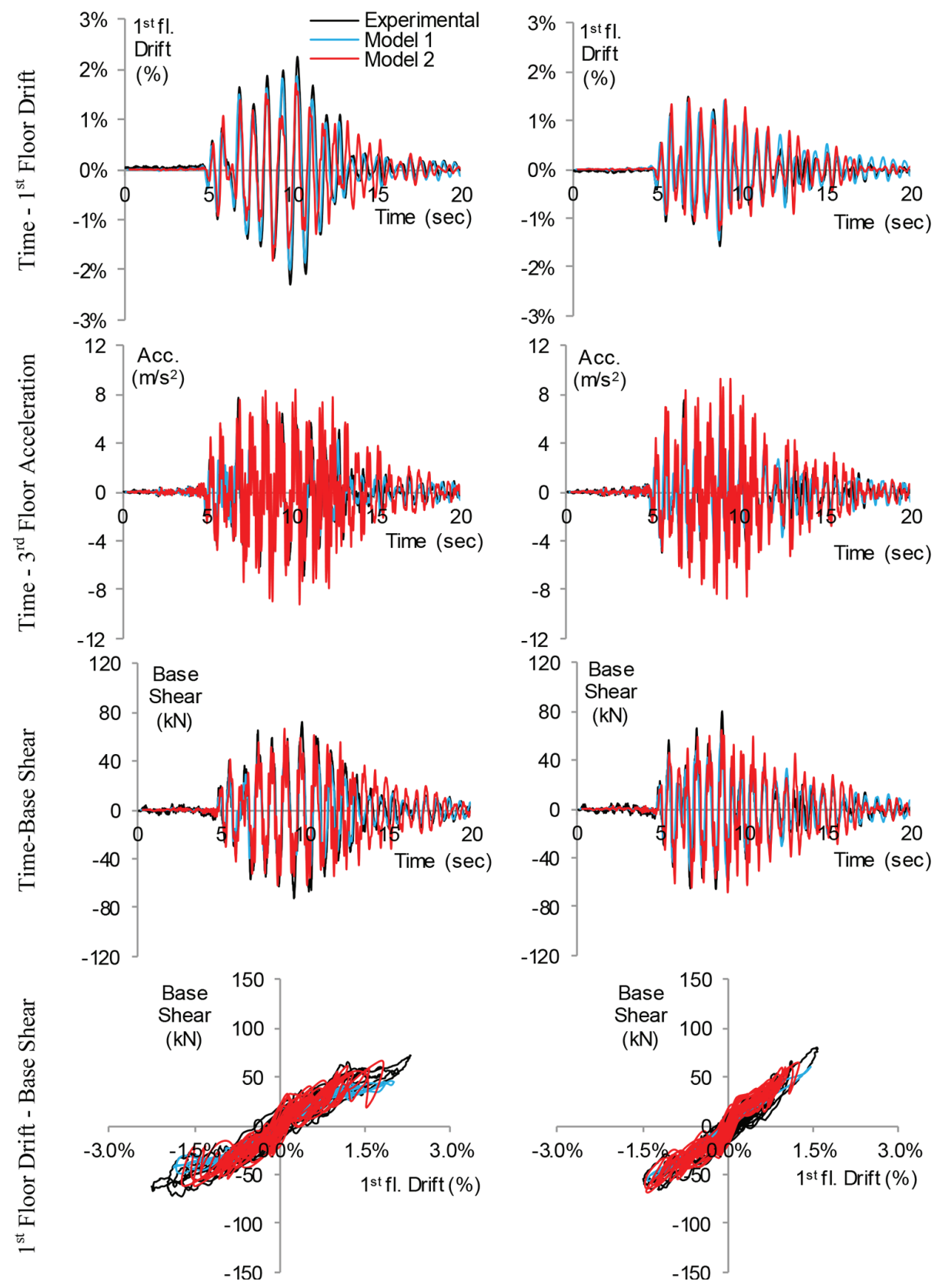

Figure 5: Testing Session 1: comparisons between experimental and numerical results of Model 1 (PB) and Model 2 (2RS) without and with dissipative reinforcing for 196 seismic input at $75 \%$ of PGA intensity. 
Testing Session 2 - Seismic Input $196-75 \%$

Without dissipation

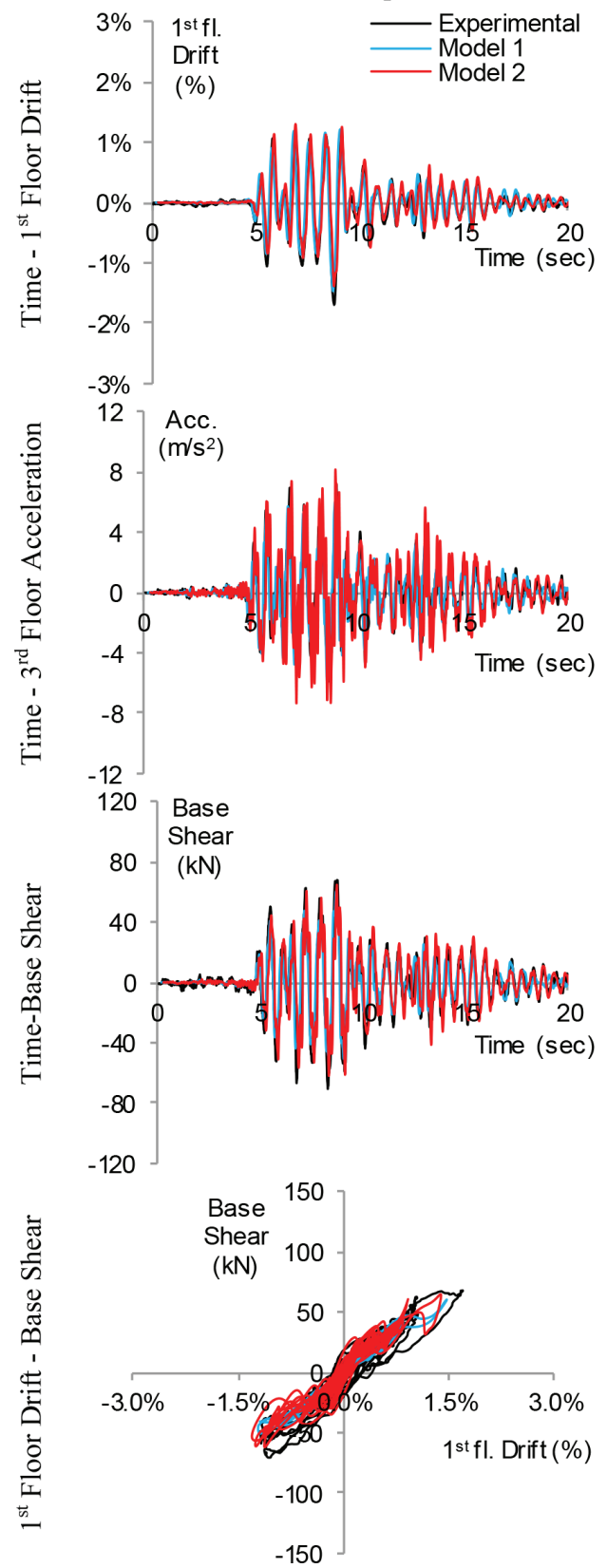

With dissipation
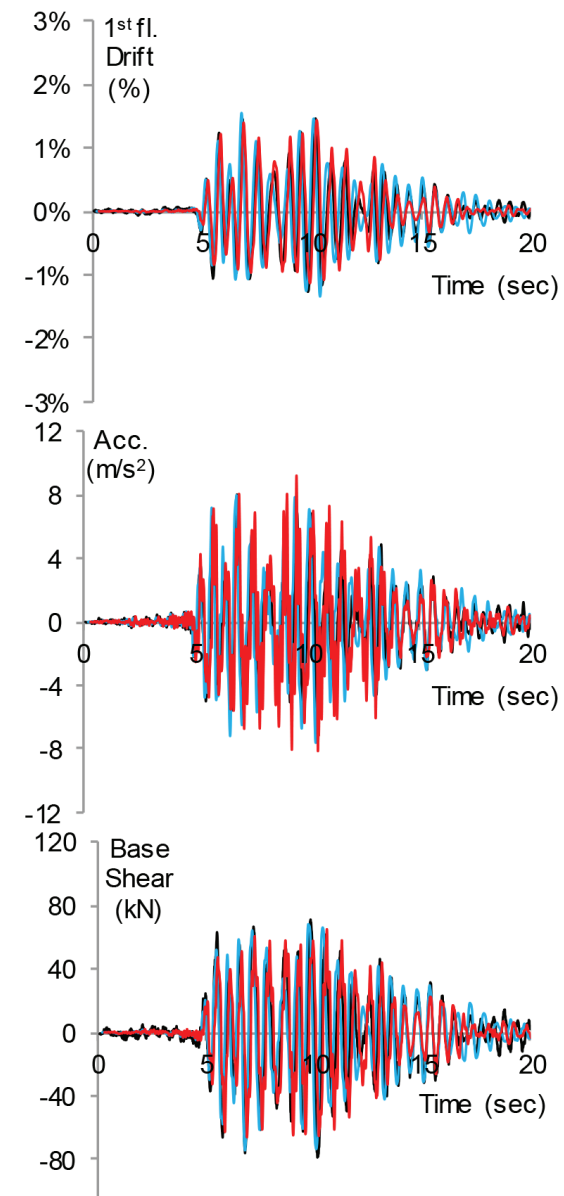

$-120$

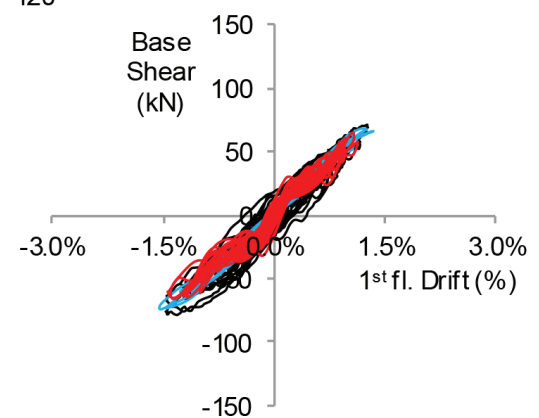

Figure 6: Session 2: comparisons between experimental and numerical results of Model 1 (MS) and Model 2 (3RS) without and with dissipative reinforcing for 196 seismic input at $75 \%$ of PGA intensity. 
Testing Session 1 - Seismic Input 535 - PGA 75\%

Without dissipation

With dissipation
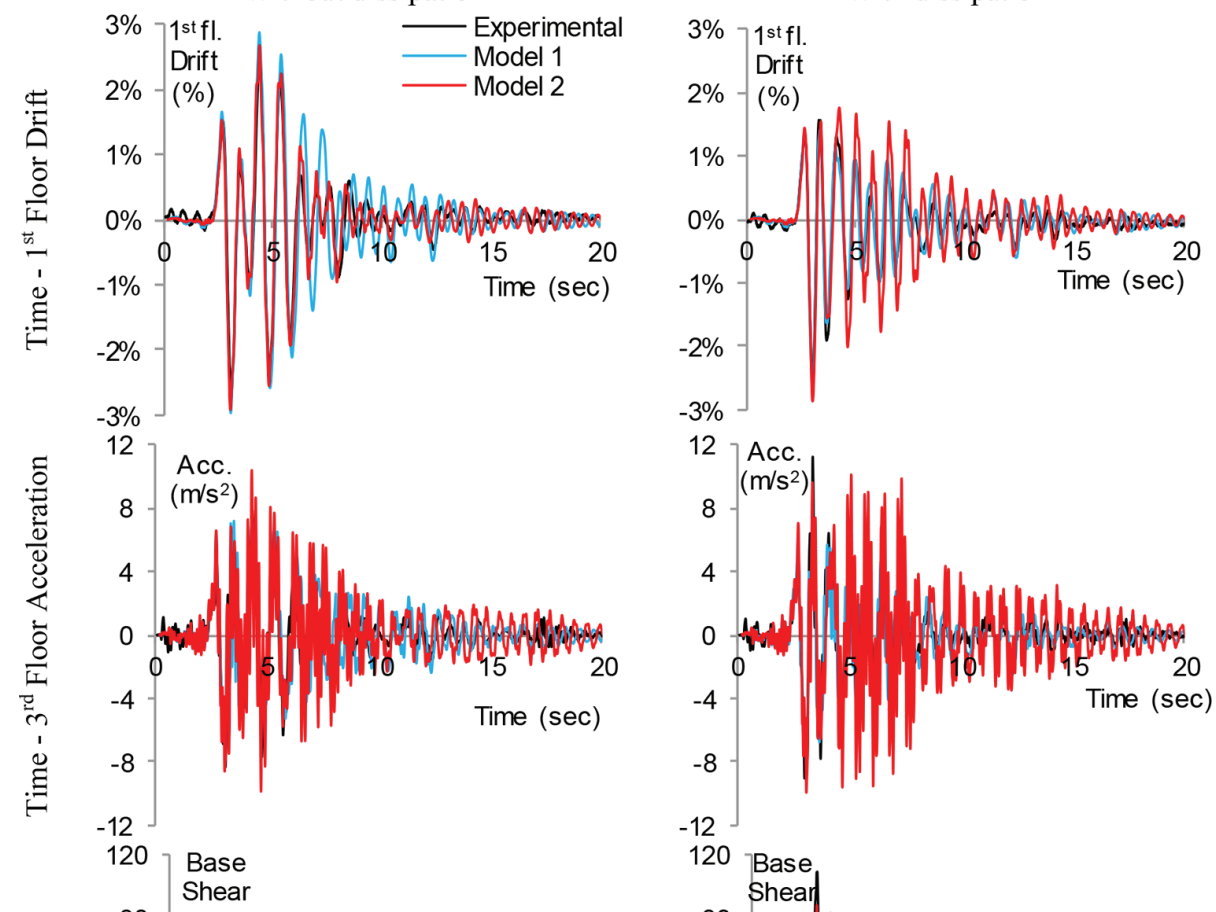

$-12$
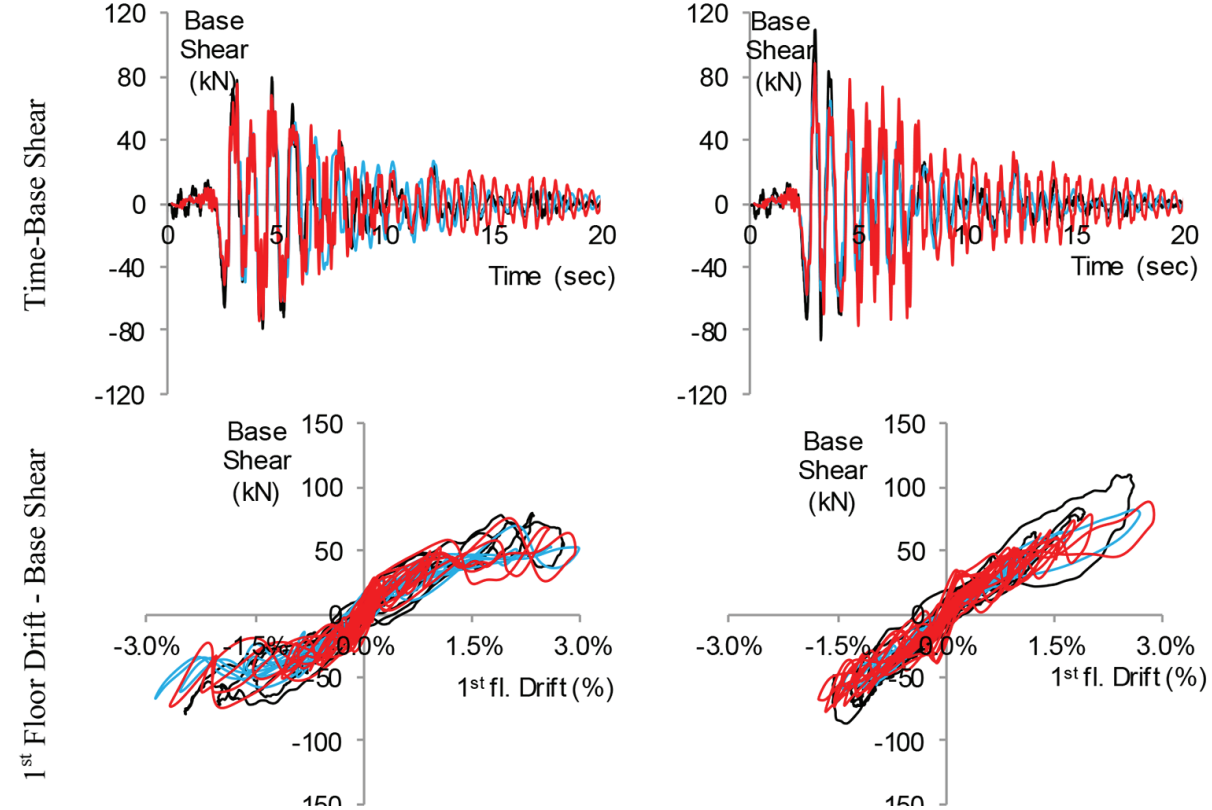

Figure 7: Testing Session 1: comparisons between experimental and numerical results of Model 1 (PB) and Model 2 (2RS) without and with dissipative reinforcing for 535 seismic input at $75 \%$ of PGA intensity. 
Testing Session 2 - Seismic Input 535 - PGA 75\%

Without dissipation

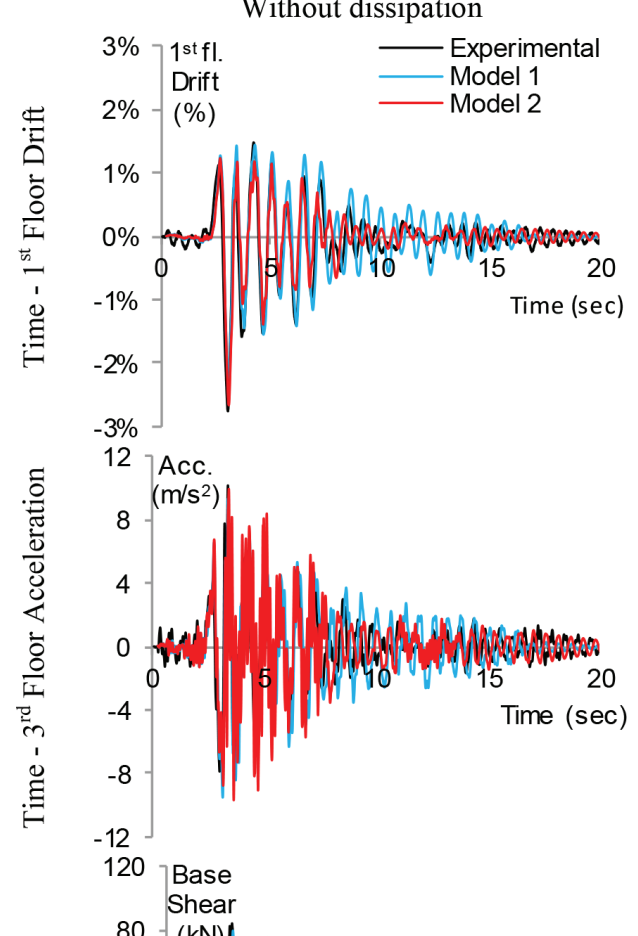

With dissipation
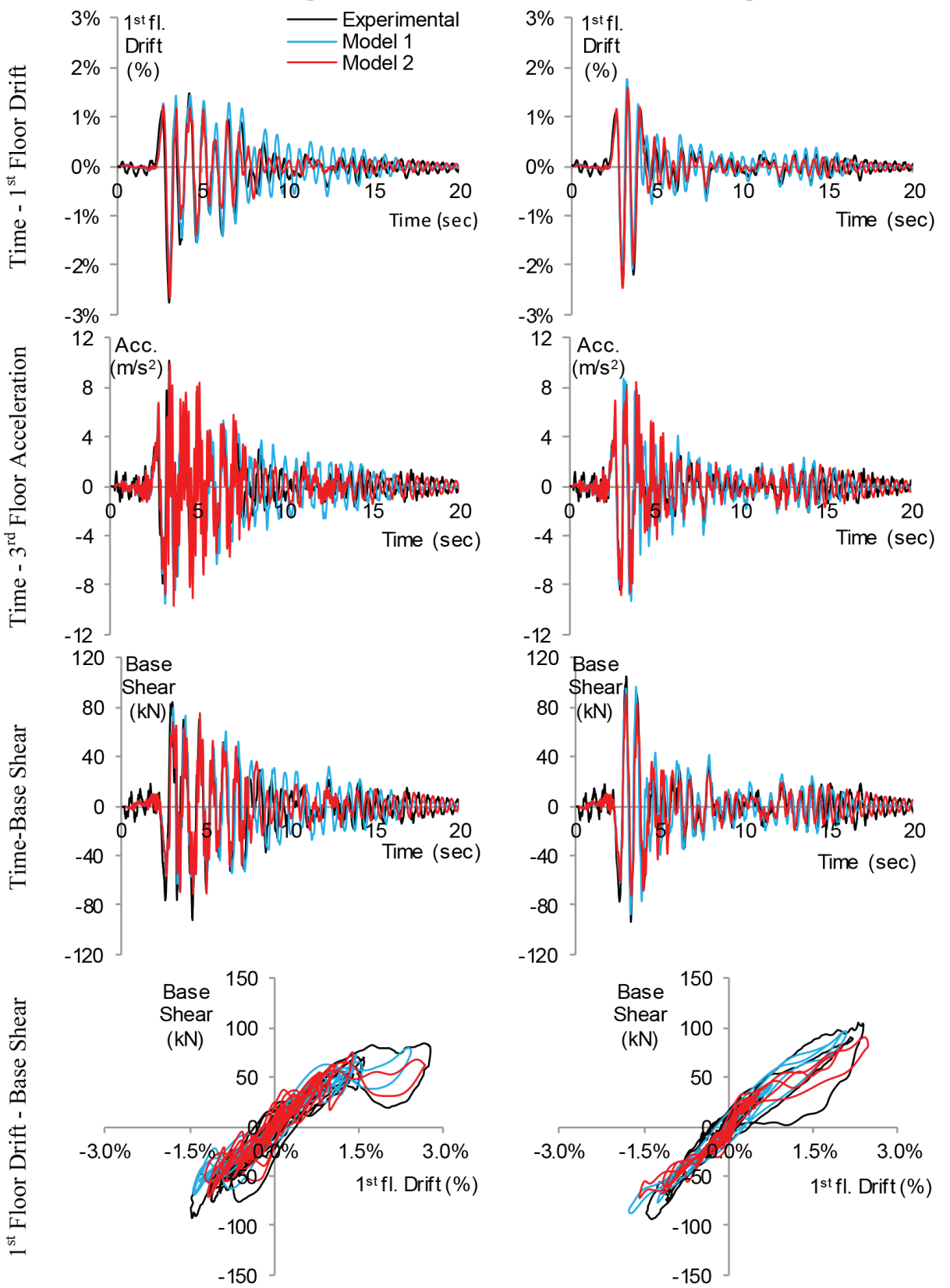

Figure 8: Testing Session 2: comparisons between experimental and numerical results of Model 1 (MS) and Model 2 (3RS) without and with dissipative devices for 535 seismic input at $75 \%$ of PGA intensity. 
For all testing sessions, the study of the base shear versus drift response shows that all numerical models approximate sufficiently well the stiffness of the test frame with and without dissipation. The comparisons between numerical and experimental results show that Models 1 and 2 provide an efficient representation of the seismic response of the testing frame with few discrepancies in terms of peak values of base shear. As can be observed for both earthquake cases analysed (196 and 535), the activation of dissipative steel devices, both at beam-column joints and at column-foundation connections, reduces discrepancies between numerical and experimental results.

\section{CONCLUSIONS}

Shaking table tests of a three-storey, two-third scaled post-tensioned timber frame have been performed at the structural laboratory of the University of Basilicata. This paper focuses on numerical modelling of the seismic behaviour of Pres-Lam timber-framed buildings with rocking mechanism at column base connections. Two different numerical modelling solutions have been considered and compared with the experimental results at four different testing configurations with and without the addition of dissipative devices both at beam-column and at column-foundation joints. In this study, two numerical models have been developed for free rocking (Session 1) and dissipative rocking (Session 2). Model 1 represents free rocking with a perfectly pinned base modelling and dissipative rocking with a multi-spring model, which is a combination of linear springs and gap elements. Model 2 represents the column-base connection through a suitable combination of two rotational springs (gravity plus seismic contributions) for free rocking, and three rotational springs (gravity and seismic plus dissipative) in order to account for dissipative rocking. Both models use the same modelling of beam-column interface, with a combination of rotational springs, opportunely calibrated. Non-linear time history analysis has been performed in order to verify the robustness of modelling in predicting the seismic response. Results have been compared with experimental records in terms of three key indicators: first level drift, third level acceleration and base shear. Numerical and experimental outcomes proved the effectiveness of both numerical models, which provide a reliable representation of both testing sessions. Only few discrepancies in terms of base shear have been found. Furthermore, few differences have been observed during testing Session 1 in case of earthquake 535 for Model 1 without dissipation and for the Model 2 with dissipation. In case of testing Session 2, both Models present an adequate representation of experimental results. The addition of energy dissipation steel angles reduces the discrepancies. Moreover, it can be observed that the rotational springs of joint panels play an important role in order to correctly account for the flexibility of rocking interface. An appropriate arrangement of the stiffness of the rotational springs could improve the performance of the modelling of the hybrid rocking mechanism during strong motions.

\section{ACKNOWLEDGEMENTS}

Authors would like to acknowledge the financial support of the Structural Timber Innovation Company (STIC, New Zealand), FederLegnoArredo (FLA, Italy) and RELUIS 2014-2016 project funded by the Italian Civil Protection Department.

\section{REFERENCES}

[1] Meek, J.W., Effects of foundation tipping on dynamic response. Journal of the Structural Division, 101(ST7), pp. 1297-1311, 1975 
[2] Chopra, A.K. \& Yim, S.C., Simplified analysis of structure with foundation uplift. Journal of Structural Engineering, 111(4), pp. 906-930, 1985

[3] Oliveto, G., Calio, I. \& Greco, A., Large displacement behavior of a structural model with foundation uplift under impulsive and earthquake excitations. Earthquake Engineering and Structural Dynamics, 32(3), pp. 369-393, 2003

[4] Midorikawa, M., Azuhata, T., Ishihara, T., \& Wada A., Shaking table tests on seismic response of steel braced frames with column uplift. Earthquake Engineering and Structural Dynamics, 35(14), pp. 1767-1785, 2006.

https://doi.org/10.1002/eqe.603

[5] Roh, H. \&. Reinhorn, A.M., Modeling and seismic response of structures with concrete rocking columns and viscous dampers. Engineering Structures, 32(8), pp. 2096-2107, 2010.

https://doi.org/10.1016/j.engstruct.2010.03.013

[6] Priestley, N., Sritharan, S., Conley, J., \& Pampanin, S., Preliminary results and conclusions. PRESSS Five-Story Precast Concrete Test Building. PCI Journal, pp. 42-67, 1999.

https://doi.org/10.15554/pcij.11011999.42.67

[7] Palermo, A., Pampanin, S., Buchanan, A. \& Newcombe, M.P., Seismic design of multistorey buildings using Laminated Veneer Lumber (LVL), NZSEE Conference, Taupo, New Zealand, 2005a.

[8] Palermo, A., Pampanin, S. \& Carr, A., Efficiency of simplified alternative modelling approaches to predict the seismic response of precast concrete hybrid systems. FIB symposium "Keep Concrete Attractive”, Budapest, Hungary, $2005 \mathrm{~b}$.

[9] Buchanan, A., Deam, B., Fragiacomo, M., Pampanin, S. \& Palermo, A., Multi-storey prestressed timber buildings in New Zealand. Journal of the International Association for Bridge and Structural Engineering, 18(2), pp. 166-173, 2008. https://doi.org/10.2749/101686608784218635

[10] Smith, T., Ponzo, F.C., Di Cesare, A., Pampanin, S., Carradine, S., Buchanan, A.H. \& Nigro, D., Post-tensioned glulam beam-column joints with advanced damping systems: testing and numerical analysis, Journal of Earthquake Engineering, 18(1), pp. 147-167, 2014. https://doi.org/10.1080/13632469.2013.835291

[11] Smith, T., Ponzo, F.C., Di Cesare, A., Auletta, G., Pampanin, S., Carradine, D., Palermo, A. \& Nigro, D., Testing of a post-tensioned glue laminated beam to column joint: experimental and numerical results. 12th World Conference on Timber Engineering. July 16-19, Auckland, New Zealand, 2012.

[12] EN 1995-1-1 (2004). Design of Timber Structures Part 1-1: General - Common Rules and Rules for Buildings. European Committee for Standardization.

[13] Di Cesare, A., Ponzo, F.C., Nigro, D., Dolce, M. \& Moroni, C., Experimental and numerical behaviour of hysteretic and visco-recentring energy dissipating bracing systems. Bulletin of Earthquake Engineering, 10(5), pp. 1585-1607, 2012. https://doi.org/10.1007/s10518-012-9363-X

[14] Di Cesare, A., Ponzo, F.C., Simonetti, M., Smith, T. \& Pampanin, S., Numerical modelling of a post-tensioned timber framed building with hysteretic energy dissipation. 5th SEMC, Cape Town, South Africa. Taylor \& Francis Group, 2013b. 
[15] EN 1998-1, Design of structures for earthquake resistance - Part 1: General rules, seismic actions and rules for buildings. European Committee for Standardization, 2003.

[16] Ponzo, F.C., Smith, T., Di Cesare, A., Pampanin, S., Carradine, D. \& Nigro, D., Shaking table testing of a multi-storey post-tensioned glulam building: design and construction, 12th World Conference on Timber Engineering, Auckland, New Zealand, 2012.

[17] Kaldjian, M.J., Moment_curvature of beams as Ramberg-Osgood functions. Journal of the Structural Division, American Society of Civil Engineers, 93(ST5), pp. 53-65, 1967.

[18] Bouc, R., Forced vibration of mechanical system with hysteresis. 4th Conference on Nonlinear Oscillations, Prague, 1967.

[19] Wen, Y.K., Equivalent linearization for hysteretic systems under random excitation. Journal of Applied Mechanics, 47(1), pp. 150-154, 1980. https://doi.org/10.1115/1.3153594

[20] Priestley, M.J., Calvi, G.M. \& Kowalsky, M.J., Displacement based seismic design of structures, IUSS, Pavia, 2007.

[21] Di Cesare, A., Ponzo, F. C., Nigro, D., Pampanin, S. \& Smith, T., Shaking table testing of post-tensioned timber frame building with passive energy dissipation system. Bulletin of Earthquake Engineering, pp. 1-24, 2017.

https://doi.org/10.1007/s10518-017-0115-9. 